\title{
Tecnologias de reprodução assistida no Brasil: opçóes para ampliar o acesso
}

\section{I ${ }^{1}$ Marilena C. D. V Corrêa, ${ }^{2}$ Maria Andrea Loyola |}

Resumo: Este artigo revisita o padrão de assimilação e difusão das tecnologias de reprodução assistida (TRA) no Brasil, caracterizado por altíssima concentração desta tecnologia no setor privado da medicina e baixíssima regulação na aplicação destas técnicas. Este padrão gerou enormes dificuldades e barreiras ao acesso a essas técnicas, basicamente por razōes econômicas. A partir da apresentação do panorama da história das TRA, o artigo focaliza dois casos que podem configurar propostas de solução para a excessiva exclusão ao acesso, ainda que não se modifique a mesma lógica privatizante que marca a RA no país, uma vez que o problema das infertilidades não foi priorizado, até o momento, no Sistema Único de Saúde. A primeira, trazida pela indústria farmacêutica, consiste em um programa de compras subsidiadas de medicamentos pelos usuários no chamado Programa Acesso. A segunda proposta, conhecida como doação compartilhada de óvulos, implica a troca, entre duas mulheres, de material reprodutivo biologicamente escasso (ovócitos). Esta troca ocorre, em geral, entre uma mulher que tem óvulos e não pode custear seu tratamento e outra que, não tendo mais óvulos para se reproduzir, custeia o tratamento da doadora. Ambas as propostas se difundem num quadro legal bastante mal regulado em termos da aplicação das TRA, mas que veda práticas não admitidas na Constituição Federal e criminalizadas na lei penal, como a comercialização de órgãos e tecidos humanos em geral, bem como pagamento a voluntários de testes para pesquisa, pela Resolução no 466 (CNS, 2012). Em termos metodológicos, o artigo assume caráter monográfico e de debate da literatura, mas está baseado também na coleta de dados secundários recentes, assim como em inúmeras pesquisas empíricas realizadas ao longo dos últimos 25 anos pelas autoras.

> Palavras-chave: reprodução assistida; tecnologia biomédica; acesso; direitos reprodutivos.
${ }^{1}$ Instituto de Medicina Social, Universidade do Estado do Rio de Janeiro. Rio de Janeiro-RJ, Brasil. Endereço eletrônico: correamarilena@gmail.com

2 Instituto de Medicina Social, Universidade do Estado do Rio de Janeiro. Rio de Janeiro-RJ, Brasil. Endereço eletrônico: loyolama@terra.com.br 


\section{Considerações iniciais}

O conjunto de técnicas, tecnologias, equipamentos, procedimentos médicos e biomédicos para a fertilização do embrião in vitro recebe denominações variadas, tais como "reprodução assistida" (RA), "reprodução humana assistida" (RHA), ou ainda "técnicas de reprodução assistida" (TRA), que, na prática, se equivalem. ${ }^{1}$ A introdução dessas TRA de alta complexidade no mundo se deu, ao longo dos anos 1970, sem que houvesse um período explicitamente considerado como de uso experimental. ${ }^{2}$ Tratando-se de tecnologias muito complexas e que intervêm em processos vitais humanos, como a reprodução e a genética, seria desejável estabelecer evidências científicas fortes e boas práticas médicas e laboratoriais antes de sua ampla difusão, o que não se verificou na prática.

O primeiro "bebê de proveta" nasceu na Inglaterra em 1978, após nove anos de registros de tentativas sem sucesso de fertilização in vitro do embrião, na literatura especializada (STEPTOE; EDWARDS, 1978). Em 1984 foi tornado público o primeiro documento ético sobre a RA, originado de um ciclo de debates entre médicos, biólogos, psicólogos e filósofos que compunham uma comissão convocada pelo Parlamento inglês, em 1982, e presidida por Mary Warnock. O trabalho dessa comissão foi publicado poucos anos mais tarde, sob a forma de um relatório (UK, 1984) e tornou-se referência histórica na área da bioética, sobretudo para os países europeus.

No período inicial da história da RAs, as técnicas se dirigiam para quadros medicamente delineados, patologias bem identificadas como a obstrução tubária, permitindo que a linguagem médica fosse hegemônica ou quase monológica. Entretanto, nessa mesma época o Relatório Warnock já antevia desdobramentos sociais, éticos e biotecnológicos, como mostram os pontos que constituíram objeto de deliberação na comissão: por um lado, antevia-se a questão da elegibilidade, ou seja, quem pode demandar acesso às TRA - pessoas sozinhas, homossexuais, etc.; por outro, discutia-se o destino de embrióes excedentes, sendo mencionadas propostas como doação, uso em pesquisas e congelamento, entre outros.

Rapidamente, a literatura socioantropológica se ampliou ao perceber que o "desejo de filhos" (HARDING 1986; IACUB, 1999; STRATHERN, 1993; CORRÊA; LOYOLA 1999; CORRÊA, 2003), independentemente de achados clínicos e patológicos em mulheres e homens, tem força suficiente para dar início a uma forte demanda por reprodução - ter filhos, formar família. Ou 
seja, o desejo de filhos conduz os indivíduos a aceitar e enfrentar os riscos (de medicamentos e procedimentos) e das limitações do sucesso das TRA. Justifica também, no âmbito médico-científico, a suspensão de provas científicas como etapa necessária à incorporação de novas tecnologias biomédicas à prática médica. Do ponto de vista ético, assim como essas técnicas nunca chegaram a ser enquadradas como experimentais, as primeiras mulheres que se submeteram às TRA nunca foram enquadradas como sujeitos de pesquisa. A RA se normalizou na prática da medicina reprodutiva sem uma etapa considerada de pesquisa com seres humanos (CORRÊA; LOYOLA, 2005).

A proposição do conceito de ausência involuntária de filhos - "childlessness" (BECKER; NACHTIGALL, 1992; BECKER, 1994) é central para a delimitação de novas situações forjadas a partir da difusão das TRA. A linguagem médica monológica inicial de tratamento do casal infértil começa a perder força, deixando cada vez mais evidente que as técnicas irão se dirigir para a correção de falhas nos projetos reprodutivos de pessoas e não exatamente ao combate de doenças ou a problemas de um casal infértil. A RA reforça, assim, as normas sociologicamente centrais para o processo de reprodução social (LOYOLA, 2005): o desejo de ter filhos e constituir famílias, de paternidade e maternidade. A reiteração dessas normas pode constituir um obstáculo ao avanço da reprodução assistida ou, ao contrário, permitir antever possibilidades revolucionárias no plano das famílias ou das formas de convivência entre os sexos (COREA, 1985; LABORIE; MARCUS-STEIFF; MOUTET et al., 1985; CALLAHAN, 1995; DENNY, 1994; GINSBURG; RAPP, 1995; INHORN, 2002; CORREAA; LOYOLA, 1999; 2005; SAMA, 2006; BUTLER, 2006).

Fato é que, para o discurso médico, foi muito importante persistir em definições, classificações e categorizações das infertilidades, uma vez que é no campo da doença que a medicina se move com autoridade prescritiva. Para a Organização Mundial da Saúde (OMS), a infertilidade era definida como ausência de gestação de casal após 24 meses de relaçôes sexuais não protegidas, tendo sido reduzida, após o surgimento da RA, para 12 meses (WHO, 2002). Estima-se entre 8 e 15\% a população de "inférteis" no mundo (SOUZA, 2008), sendo que, além de amplo, sob este intervalo há categorias que variam de forma significativa (de "causas bem estruturadas" a indeterminadas). Quando "bem estruturadas", as causas são categorizadas também por sexo, sendo $40 \%$ consideradas de origem 
masculina, $40 \%$ de origem feminina, $15 \%$ decorrentes da combinação de ambos, e o restante sem causa aparente ou "dificilmente identificada" (Biazotti citado por COSTA, 2014). Não resta dúvida de que um problema que impede a reprodução biológica pode ser e vem sendo medicamente delimitado (esterilidade tubária, anovulatória etc.). Mas, diferentemente de outras situações que envolvem a interferência médica, no caso das TRA a percepção de um desejo insatisfeito é um elemento fundamental que se apresenta e se manifesta desde o início das consultas, e dentro de um processo de interação entre médico, paciente, amigos e familiares. Neste caso, a doença "vai sendo configurada por meio da percepção de sinais - o desejo não satisfeito por filhos - na interação médico-paciente" (COSTA, 2014, p. 1).

\section{A inovação: uma abordagem sociotécnica}

A exposição de óvulos (células reprodutivas femininas) fora do corpo da mulher com vistas à sua fertilização pelo sêmen (material reprodutivo masculino) em uma placa constituiu um fato científico novo - a fertilização in vitro (FIV) do embrião. Essa forma de fertilização, que passou a ocorrer em ambiente laboratorial, tornou o embriāo humano um objeto técnico (CORRÊA, 1997).

O suporte laboratorial para manipulação das células reprodutivas e do embrião conta com a participação de biólogos e biomédicos que se acoplaram às clínicas convencionais de ginecologia e obstetrícia (G\&O), transformandoas. Progressivamente, o campo da reprodução assistida se autonomizou da especialidade à qual esteve ligada ( $\mathrm{G \& O})$, com tudo que isso implica, em especial a criação de associações profissionais nacionais, regionais e internacionais específicas.

As TRA são também um campo pioneiro do que veio a se tornar a tendência dominante de organização comercial e mesmo industrial da biotecnologia, com seus processos de intervenção e apropriação da vida (HARAWAY, 1991; CORREA, 1997; FRANKLIN; RAGONE, 1998; DAVIS-FLOYD; DUMMIT, 1998; SAMA, 2010).

A partir dos anos 2000, consolida-se a tendência de desenvolvimento de pesquisas com células-tronco, pesquisas genéticas sobre células primordiais, testes genéticos a serem aplicados sobre embriōes para controle de supostos traços desejáveis e o aniquilamento de indesejáveis. Essas pesquisas se tornaram factíveis 
porque o embrião humano "saiu" do corpo da mulher, se expôs em laboratórios a técnicos, que não se sujeitam mais apenas à lógica reprodutiva do desejo de filhos e famílias, mas à lógica da intervenção científica, com seus impulsos próprios e modos de organização atuais (Corrêa 2005a). Óvulos, estruturas mitocondriais, sangue do cordão umbilical, traços genéticos identificáveis em testes, linhagens de células-tronco isoladas, etc. se tornaram materiais de pesquisas que podem vir a ser apropriadas para fins de trocas comerciais - como permitem certos arranjos da "doação" compartilhada de óvulos -, ou até mesmo ser apropriados por dispositivos como as patentes, o que já ocorreu no caso de linhagens de célulastronco consideradas "promissoras".

Como proposto por Corrêa (1997), acontecimento sociotécnico central do mundo da reprodução assistida, o embrião in vitro é particularmente revelador de como se fundem e se confundem diferentes lógicas construídas a partir de objetos e interesses diferentes (social, médica, científica, comercial, industrial), trazendo novos e importantes desafios à cena biopolítica. A reprodução biológica, antes impedida pelas "infertilidades sem cura" agora é viabilizada pelas técnicas biomédicas. Por isso, a FIV foi apresentada e representada na mídia, na literatura, no cinema e no discurso de vulgarização científica, pelos próprios especialistas como a revolução da vida do século XX.

Essa revolução, para se viabilizar, pode, entretanto, exigir que para além da participação dos biomédicos, se tenha de passar por complexos arranjos reprodutivos e contar com vários participantes de áreas não médicas - homens e mulheres interessados - doadores e receptores de sêmen, óvulos, embrióes, úteros, citoplasmas, etc. A aplicação das TRA traria assim, potencialmente, uma revolução da parentalidade, e mais profundamente, do próprio sistema reprodutivo tal como o conhecemos (LOYOLA, 1992). Ambas (revoluçôes) vão emergir e depender, em parte do contexto e em parte da regulação dos efeitos sociais, legais, éticos e bioéticos do uso das inovações e dos arranjos reprodutivos colocados pelas técnicas.

Bem longe da linguagem médica do tratamento da infertilidade de um casal, vemos hoje que as inovações reprogenéticas vão ao encontro de indivíduos informados, consumidores, por vezes organizados em associaçōes em torno de problemas semelhantes. Nesse modelo, o desejo de reprodução pode reescrever um mundo novo e já vem provocando deslocamentos e redefiniçôes dos problemas 
propriamente ditos, como na proposição da categoria da ausência involuntária de filhos. Esta pavimenta, por exemplo, a demanda de filhos por homossexuais. Mas as TRA podem também promover a seleção sexual, pela escolha predeterminada do sexo, o que por si só traz uma profunda alteração do sistema de regulação da vida e da reprodução, onde cada um pode e deve gerir o capital saúde próprio e de sua descendência; seus sucessos, riscos e revezes, escolhas das quais devem estar conscientes.

\section{Gestão do capital reprodutivo}

Se compararmos o papel de homens e mulheres na reprodução biológica, não há dúvida de que as manipulações médico-cirúrgicas e os riscos incidem muito mais ou quase exclusivamente sobre o corpo das mulheres. O ciclo FIV se inicia com a hiperestimulação hormonal da mulher, pelo uso de drogas injetáveis que visa propiciar o amadurecimento de um grande número de ovócitos. Segue-se uma fase de monitoramento, que consiste em ultrassonografias repetidas até serem coletados os ovócitos considerados maduros. O objetivo da hiperestimulação hormonal (etapa 1 da FIV) é tornar disponível elevado número de células reprodutivas femininas (e não um folículo ovariano apenas, como ocorre biologicamente a cada mês). A ideia é disponibilizar muitos ovócitos para aumentar a chance de se obter número elevado de embriōes passíveis de serem viáveis para serem fertilizados in vitro e depois transferidos. A FIV é, então, um processo que produz células reprodutivas femininas e embriōes excedentes, em número muito maior do que aquilo que demandariam as pessoas: um bebê. ${ }^{3}$

Passados quase 40 anos de aplicação de TRA de alta complexidade, os biomédicos ainda enfrentam problemas com o relativamente baixo sucesso global (resultados) das TRA, vis-à-vis as manipulações invasivas, custos e riscos nelas implicados. Efetivamente, a FIV opera ainda em um regime de tentativas e erros, o que indica que não se detém know-how para produzir controladamente apenas um embrião in vitro e garantir sua viabilidade. ${ }^{4}$

Em busca de maior eficácia com as técnicas, podem ser transferidos para o corpo da mulher mais que 1 - ou seja, 2, 3, 4 embrióes, ou mesmo mais que isso, dependendo do estado da arte em termos de regulação, ética e de boas práticas, do contexto em questão. Essa forma de proceder vai gerar as gestações múltiplas, altamente indesejadas; ou, não sendo transferidos e implantados imediatamente 
no corpo da mulher que demanda reprodução, os embriōes excedentes, como apontado, serão congelados, eventualmente doados para outras pessoas ou para pesquisas, ou mesmo destruídos.

Não cabendo alongar aqui este debate, apontamos apenas as duas etapas mais críticas para a saúde do ciclo FIV: a hiperestimulação hormonal pelas altas doses de hormônios exigidas, com riscos e efeitos colaterais penosos e efeitos ainda mais graves para mulheres e fetos, como as gestações multigemelares. Estas se tornaram tão comuns e iatrogênicas no campo da RA que a crítica ao filho a qualquer custo acabou por vir de dentro do próprio campo da medicina, forçando uma revisão por parte de alguns dos especialistas em RA em suas práticas, sobre o número máximo de embriōes a serem transferidos no ciclo FIV. (ANGEL et al., 1999; ANNAS, 1998; BAIRD; WICOX; KRAMER, 1999; CRAFT et al., 2000; FRITSIMMONS; BEBBINGTON; FLUKER, 1998, TE VELD; VAN BAAR; VAN KOOIJ, 1998; VAN STEIRTEGHEM, 1998; WHO, 2002).

Combatidas na regulação europeia e norte-americana, as gestações multigemelares ainda se apresentam em taxas muito altas no Brasil e na América Latina, com consequências negativas de toda sorte para a saúde da mulher e para os bebês. Como mostram os relatórios anuais da Rede Latino-Americana de Reprodução Assistida (Rede LARA) - que empreende um esforço muito relevante de monitoramento da aplicação das técnicas de RA na região -, os bebês nascidos por essas técnicas apresentam baixo-peso, são prematuros (em taxas mais elevadas que os nascimentos em geral), o que exige internações prolongadas em UTI neonatais.

Apesar destes revezes, sendo o ciclo tecnológico inexoravelmente exponencial, a possibilidade do embrião in vitro deu lugar a propostas como a de diagnóstico pré-implantatório do embrião (DPI). Este não deve ser confundido com o chamado "diagnóstico pré-natal", que compreende técnicas mais antigas e bem difundidas nos pré-natais, inclusive na rede pública (Sistema Único de Saúde - SUS) como: amniocentese, cariótipo, etc. Já no DPI, a partir de uma biopsia do embrião in vitro, a tecnologia diagnóstica é aplicada para selecionar doenças e sexo, ou como um dispositivo de delineamento de características e atributos humanos: "potencialidade de traços, do que seja um ser humano normal, aceitável ou valorizado segundo seus genes" (LOWY 2013, p. 1). Na maior parte das vezes, esses traços são suspostamente de base genética. A identificação de traços mais ou 
menos negativos, ainda que em termos probabilísticos, ou pior, especulativos, levaria à eliminação de embriões.

\section{A saga reprodutiva da RA no Brasil}

As primeiras usuárias brasileiras de FIV, inseridas em experimentos desta inovação, ditas "voluntárias", residiam em sua maioria na cidade de São Paulo, onde se encontravam em maior número os primeiros especialistas de RA. A incorporação dessa biotecnologia se deu por meio da organização privada de pequenos seminários, para aquisição de know-how. O convite era feito por grupos de clínicas e especialistas nacionais a renomados especialistas estrangeiros, que custeavam a vinda e o trabalho dos mesmos no Brasil para ensinar aqui como aplicar as tecnologias que compõem a FIV: medicamentos, doses e formas de usar concebidas como mais favoráveis à época, meios de cultura a escolher, etc. $\mathrm{O}$ trabalho desses médicos estendia-se inclusive ao monitoramento à distância da evolução das gestações de mulheres brasileiras. De fato, muitas daquelas mulheres "voluntárias" aceitaram submeter-se aos procedimentos em tais condiçôes de aprendizado dos especialistas por não poderem pagar pelo tratamento. Este foi o caso do primeiro nascimento de um bebê FIV brasileiro, em 1984. Na época, tais condições foram denunciadas nacional e internacionalmente na literatura feminista e de cunho sociológico sobre a mulher (REIS, 1985; COREA, 1985; ROWLAND, 1987; SCUTT 1990), inclusive o caso de morte de uma voluntária.

A despeito de contradiçôes sanitárias, éticas, legais e mesmo de controvérsias científicas que permearam a história das TRA, o valor social atribuído à reprodução (maternidade e paternidade), à família geneticamente relacionada, à vida doméstica de base familiar sob os mais diversos tipos de arranjo e vínculos biogenéticos, o valor atribuído ao desenvolvimento pessoal por meio da reprodução são fatores a reforçar o desejo de filhos como algo altamente bemvindo e socialmente legítimo, a justificar o clamor pelo "acesso às TRA a qualquer custo". Desta forma, a revolução reprogenética foi rapidamente naturalizada e normalizada como uma prática médica comum, como um "mero" tratamento, o que permitiu as TRA serem dissociadas da ideia de experimentos ou de pesquisas com seres humanos, mesmo que a medicina reprodutiva permaneça um campo híbrido, entre clínica e experimentação, já que há permanente incorporação de novas tecnologias no campo. Essa naturalização da tecnologia chegou a tal ponto 
que a linguagem social da reprodução e a linguagem médica das infertilidades

vão acabar por se associar no bordão: "as pessoas trazem os desejos e a medicina, as técnicas" - usados pelos especialistas em entrevistas, na mídia, em papers, e também por usuários em entrevistas.

No Brasil, após longo vácuo no plano de políticas públicas sustentadas para RA no SUS, duas versões de uma portaria do Ministério da Saúde foram formuladas, em 2005 - "Atenção integral à reprodução humana assistida no SUS" (BRASIL, 2005a; 2005b) - e acabaram não sendo implantadas. Ao contrário, foram revogadas em curto espaço de tempo, por falta de priorização na alocação de recursos, ainda que enfatizassem a aplicação da TRA de forma restritiva e medicamente identificada, como na prevenção da transmissão do HIV no caso da demanda de procriação por casais sorodiscordantes.

Ao fim e ao cabo, a questão do acesso e da elegibilidade - quem tem direito de usar TRA - está por ser solucionada em uma luta social por direitos. Esperar-se-ia que o problema da ausência de filhos tivesse sido dirigido pelo SUS, considerando seus princípios fundamentais, como a definição ampliada de saúde e a visão de integralidade da atenção, exigidos nos conteúdos programáticos das políticas públicas em saúde no país. Deve ficar claro que tais princípios ultrapassam, no nível das práticas de saúde, a proposta heurística aqui avançada, no plano das ideias, de uma diferenciação entre a categoria da ausência involuntária de filhos, oriunda da pesquisa socioantropológica aplicada à saúde e definiçôes biomédicas da infertilidade. Os deslocamentos que os princípios do SUS produzem no campo da Saúde Pública no Brasil, produzindo e promovendo uma concepção ampliada de saúde e bem-estar, permitem acolher a questão, sob um ou outro dos termos.

Soma-se o arcabouço jurídico-normativo brasileiro, com destaque para a Lei do Planejamento Familiar (LPF), em vigor no país há quase duas décadas, a Lei no 9.263/1996 (BRASIL, 1996) prevê direitos reprodutivos amplos, no âmbito do SUS. Nela se lê, em seu artigo 10: "o planejamento familiar é direito de todo cidadão, e ele $[\mathrm{PF}]$ é entendido como conjunto de ações de regulação da fecundidade que garanta direitos iguais de constituição, limitação ou aumento da prole pela mulher, pelo homem ou pelo casal" (grifos nossos). E em seu artigo $3^{\circ}$ : $\mathrm{O} P F$ "deve ser parte do conjunto de ações integrais de atenção à mulher, ao homem ou ao casal, dentro de uma visão de atendimento global e integral à saúde". Além da consagração da saúde como direito fundamental inscrito na 
Constituição Federal, existe lei específica na área que permite garantir direitos individuais à regulação da fecundidade, assim como acesso aos meios necessários para tal, dentro do SUS.

Em função disso, não são poucos os casos já levantados de judicialização ${ }^{6}$ - processos judiciais demandando que o Estado pague pela FIV a cidadãos usuários do SUS. Mas inversamente a outros casos de medicamentos e doenças, os juízes vêm negando com elevada frequência o custeio da FIV, sendo um dos argumentos mais utilizados que a ausência de filhos não é uma doença. Ademais, como evidencia o exame da jurisprudência, o entendimento do que seja planejamento familiar tem sido restritivo, ficando muito voltado aos direitos de acesso à contracepção, o que não se coaduna com a lei específica, nem com os princípios constitucionais e os do SUS.7.

Há também o problema de fraquíssima regulação específica da RA no país. Mencionados isoladamente alguns casos de figura no novo Código Civil brasileiro (inseminação post morten, inseminação artificial heteróloga), não houve nem legislação sobre consequências de conflitos no âmbito da filiação, patrimônio, etc. (BRASIL, 2003). Existem projetos de lei que não tramitam mais no Congresso Nacional. Como referência para a aplicação das TRA, existe em vigor apenas norma ética de órgão médico, o Conselho Federal de Medicina (CFM), que emitiu a primeira em 1992 (CFM, 1992), reviu-a com algumas alterações em 2010 (CFM, 2010), estando em vigor aquela do ano de 2013 (CFM, 2013). Além desta norma profissional, autodefinida como de cunho ético, não existiam outros dispositivos regulatórios para enquadrar o uso da reprodução assistida e seus efeitos no país. O que se lê ali é, por um lado, uma preocupação de, em nome da ética médica, franquear o acesso a qualquer pessoa, independentemente de estado marital ou sexualidade dos envolvidos (já que todos os arranjos são explicitamente admitidos - doação de material reprodutivo, de embriāo, "empréstimo de útero", bem como a demanda por pessoas sozinhas, homossexuais). Quanto à questão dos riscos das gestações múltiplas, a norma do CFM é bastante discreta, sugerindo que se evite a transferência de mais de dois embriōes, mas sem que haja vedação ou obrigatoriedade.

Pode ser esperada uma evolução importante de certos aspectos no plano da regulação, diretamente ligados à sequência de leis, normas e portarias surgidas com a promulgação da Lei de Biossegurança (Lei no 11.105), revista em 2005, que 
admitiu a cessão de embriōes congelados para pesquisas. Bastante tardiamente surgiram iniciativas e resoluções normativas da Agência Nacional de Vigilância Sanitária (ANVISA): em 2006, foi criado um sistema de informaçōes sobre embriôes congelados no país (Sisembryo); e em 2011, normas para as condições mínimas de funcionamento das clínicas. Esse movimento regulatório na área da saúde pública está todo voltado para o controle dos embriōes congelados um ente sem estatuto jurídico definido (pessoa ou coisa?). Sendo as clínicas de reprodução assistida a única fonte deste novo material de pesquisa - os embriōes congelados -, elas passam a ser alvo de uma regulação mais direta pela ANVISA. Entre outros objetivos "menores", estas iniciativas podem incluir a garantia de produção de bons embriôes para pesquisa. Entretanto, todos os efeitos clínicos (riscos de gestações múltiplas), sociais (definição da parentalidade e formas de famílias) resultantes da aplicação das TRA, sem falar nas trocas de material reprodutivo entre as pessoas (FACCHIN, 2003), permanecem desregulados nos respectivos âmbitos jurídicos.

\section{Discussão: novas soluções para o acesso?}

No Brasil, até o momento, a principal exclusão do acesso à FIV é de base econômica: o custo dos bebês de proveta os torna inacessíveis a uma enorme parcela da população interessada. As pessoas já frustradas em seus projetos reprodutivos, por razões adicionais - basicamente a indisponibilidade de técnicas de alta complexidade no setor público (SUS) - têm sua situação de vulnerabilidade moral e social agravada (COSTA et al., 2009).

Dois estudos recentes sobre o caso brasileiro (ALFANO, 2014; SOUZA, 2014) analisaram a oferta de TRA no setor público, evidenciando o baixíssimo alcance dos poucos serviços existentes, tanto em termos das técnicas disponíveis quanto das longas filas de espera (além dos diversos critérios a serem observados para inclusão nessas listas). Alfano (2014), estudando o Estado do Rio ,,,,de Janeiro, encontrou, a partir de sites da internet, referência a atendimentos a infertilidades nos seguintes hospitais: Hospital Universitário Antônio Pedro (Faculdade de Medicina da Universidade Federal Fluminense); Instituto de Ginecologia/Universidade Federal do Rio de Janeiro; Santa Casa; Hospital Universitário Pedro Ernesto (HUPE/UERJ). Nenhum dos serviços destes hospitais oferece tecnologias reprodutivas de alta complexidade pelo SUS. A 
autora também entrevistou responsáveis e outros profissionais de saúde nos dois principais serviços do Rio de Janeiro, observando que o que é ofertado, na grande maioria, é pesquisa diagnóstica para avalição de condições de infertilidade em mulheres que informam dificuldade para engravidar; avaliação; tentativas de indução da ovulação (para as que podem pagar por medicamentos); controles ultrassonográficos; ensino da técnica de relação sexual programada; tratamento cirúrgico (laparoscópico, histeroscópico, microcirurgia de trompas), se for o caso, dentre outros procedimentos menos complexos que excluem a FIV. Um serviço contava com unidade para inseminação artificial sem nunca ter tido um só caso bem-sucedido ao longo de mais de dez anos.

Em trabalho sobre a disponibilidade das TRA nos SUS, analisando um universo de estudo que cobriu dados para todo o país, Souza (2014) mostrou que em cerca de $5 \%$ da demanda o atendimento é feito no setor público; e que os poucos hospitais públicos ou universitários que oferecem esses serviços dificilmente conseguem custear todas as fases de tratamento de alta complexidade da FIV. Em alguns casos, eles contam com a participação financeira de usuários para a compra de medicamentos ou, no caso de hospitais universitários, com verba de pesquisas. A regra geral é a existência de enormes filas para início do tratamento. Em suas conclusóes, Souza traz como proposta de ampliação do acesso à compra de ciclos FIV pelo SUS de clínicas privadas já instaladas, dado o atraso em termos de equipamento e pessoal treinado em hospitais públicos. Trata-se de uma proposta coerente, haja vista que já é posta em prática no caso de outras patologias ou tratamentos complexos, como a hemodiálise, por exemplo.

As TRA de alta complexidade estão fora também do chamado setor de saúde suplementar (planos e seguros de saúde), o que reforça o impacto negativo sobre o acesso. Assim, a perspectiva privatizante "pura", largamente dominante na reprodução assistida no país, persiste. Outras respostas ao problema do acesso emergiram no setor, paralelamente ao circuito oficial, como nos dois casos comentados a seguir.

I) A primeira diz respeito a uma forma não regulada de comercialização da RA, o chamado Programa Acesso (a seguir, referido apenas como Programa). Instalado no país em 2005 e financiado por laboratórios farmacêuticos, seu objetivo é "gerenciar benefícios em drogas farmacêuticas" (to manage benefits 
in pharmaceutical drugs), o que significa conferir descontos na compra de medicamentos para pessoas definidas como pacientes que apresentam "condições dificultadas de procriação" (impaired conception). Os beneficiários do Programa têm "acesso" basicamente às drogas usadas regularmente na RA a preços menores que os do mercado.

E para que o Programa possa operar (vender os hormônios que fabrica), os serviços médicos têm que reduzir seus preços, relativamente ao que seria cobrado pelo prestador privado no mercado da medicina reprodutiva. Ou seja, o Programa opera em associação com clínicas de FIV previamente habilitadas pela própria firma farmacêutica. A inclusão como beneficiário se dá de duas formas: as pessoas acessam diretamente o website $e^{8}$, em sua primeira visita, devem se identificar por meio do preenchimento de um formulário com dados pessoais. Na mesma página web, é pedido ao usuário que indique um médico e/ou clínica, dentre os habilitados para atuar no Programa, listados no site operado pela firma farmacêutica e, no caso de o usuário saber que seu médico é associado ao Programa, basta indicá-lo. A segunda forma é receber diretamente do Programa a indicação de um médico assistente, igualmente acreditado pela firma, quando o primeiro contato com o Programa de RA foi diretamente no site e não por sugestão do médico. A decisão final sobre se o indivíduo é elegível cabe à firma e o critério, mais uma vez, é basicamente econômico: não ser muito pobre nem muito rico, ou seja, possuir renda ou soma de dinheiro suficiente para levar a cabo o processo, o que pode ser avaliado por intermédio dos dados pessoais coletados no site sobre profissão, emprego, imposto sobre a renda declarada etc., de modo a ser capaz de pagar, ainda que com desconto, medicamentos, serviços e exames médicos. Mas não pode ser desprovido de recursos econômicos que impeçam essas aquisições.

De fato, tomamos conhecimento, em pesquisas anteriores, de que o Programa Acesso da Merck é um braço de uma iniciativa comercial e industrial muito mais ampla das grandes companhias farmacêuticas internacionais, intitulado Vidalink. Como se lê em seu website, a Vidalink disponibiliza medicamentos das dez maiores companhias farmacêuticas e de outras, vendidos com desconto diretamente ao consumidor. Os fundadores de Vidalink, situados nos Estados Unidos da América, identificaram o Brasil como o maior mercado BPM (Pharmacy Benefits Management) potencial fora daquele país, baseado no fato de que o país tem o 
segundo maior mercado farmacêutico privado do mundo. $\mathrm{O}$ braço brasileiro de Vidalink reivindica ter adaptado sua tecnologia de gestão (BPM) ao que chama de "as necessidades do setor saúde do Brasil: redução do preço do medicamento comprado diretamente pelo usuário", também mencionando "aumento da adesão, controle da automedicação..."?

Uma resposta como esta deve ser vista como solução altamente conflitante com os princípios do direito à saúde em nosso país. Mesmo com as dificuldades enfrentadas pelo SUS, a principal orientação das políticas de saúde pública é a de expandir os gastos com a cobertura de saúde, em todos os campos da medicina, e da assistência farmacêutica, da forma mais inclusiva possível.

II) Uma segunda resposta a demanda por acesso é a chamada doação compartilhada de óvulos, que acontece no país pelo menos desde 1995 (LOPES, 1995). A doação "simples" de gametas, embriōes ou útero tornou-se prática legítima e comum no campo da reprodução assistida, desde seu início. $\mathrm{O}$ recurso à doação configura uma das formas ditas heterólogas das TRA: quando terceiros doadores ou fornecedores de material reprodutivo se fazem necessários. Já a dita "doação compartilhada", como já apontamos implica uma "troca” entre duas mulheres: uma doadora que vai "doar" seus óvulos a uma segunda mulher (receptora) que pagará por seu tratamento reprodutivo.

A aplicação da doação compartilhada, no caso do Brasil, se dá num contexto semelhante ao de países como Índia, Paquistão, Egito, Tailândia, que associam (i) elevadíssima concentração de riqueza com altos diferenciais socioeconômicos da população como um todo; (ii) diferentes padrôes de hipo/infertilidade em coexistência. Com base nos poucos estudos de caso disponíveis, podemos imaginar um modelo hipotético de "doação" compartilhada que envolveria uma mulher mais jovem, em geral portadora de problemas tubários (decorrentes de doenças sexualmente transmissíveis não tratadas, abortos de repetição em condições insalubres - condições que levam à fibrose das trompas) e, do outro lado, a receptora, uma mulher mais velha, com hipofertilidade de base hormonal (condição naturalmente compatível com a idade).

A associação entre esses dois conjuntos de fatores de ordem diversa socioeconômica e médica - somada à indisponibilidade de TRA no setor público, coloca indagações éticas sobre o que significa falar de escolha nestes 
contextos. ${ }^{10}$ Ademais, alguns juristas caracterizam a doação compartilhada como uma comercialização velada de óvulos, configurando, assim, uma ilegalidade. $\mathrm{O}$ "desvio é agravado, ainda, pela figura da intermediação do médico, que se beneficiaria em tal tipo de negociação" (CIOCCI; VIANA; BORGES JR, 2009, p. 35). Se caracterizada como ilegal, ficam invalidados, por consequência, os termos de consentimento que eventualmente tenham sido assinados para a aplicação de técnicas e os arranjos entre as pessoas. Mais ainda, se for configurado constrangimento, inclusive psicológico, no processo de escolha informada de alguma(s) das partes envolvidas, o ato pode ser caracterizado como crime, previsto no Código Penal Brasileiro. No plano do direito civil, inúmeras consequências dessa prática poderão vir a ser objeto de ações judiciais quando e se, a posteriori, os envolvidos se sentirem prejudicados por procedimentos médicos aproximados ao comércio ou a coisificação da pessoa, entre outros.

Como dito, não há uma boa estimativa da magnitude das práticas da ovodoação simples, e menos ainda da doação compartilhada de óvulos; tampouco da percepção dos participantes sobre tais trocas no país (DONADIO 1999a; 199b; PARANAMES; FRANCISCO; ALMADA-COLUCCI, 2014; RIBEIRO et al., 2007; CAVALCANTI, PEREIRA et al., 2005). Para dar uma ideia da magnitude, a partir de dados existentes confiáveis, segundo a 24a . Edição do Relatório Anual da Rede LARA publicado em 2012 (ZEGERS-HOCHSCHILD et al., 2014), a ovodoação na América Latina representa cerca de 15\% das transferências de embriōes (5.396 casos). O Brasil contribui com o maior número de clínicas, cerca de $50 \%$ para a região, segundo o relatório, que também indica apenas 57 clínicas brasileiras acreditadas pela rede (a mídia fala em quase 200, em todo o país). Sem dúvida, um procedimento complexo e sofisticado não deve ter lugar em todas as clínicas, mas sobretudo nas que não são acreditadas pela rede.

No debate biomédico, a aplicação das TRA deixou evidente o problema que se codificou como de escassez de ovócitos. De fato, a mulher nasce com um potencial de produção de óvulos que se esgota. Soma-se a este fato a tendência sociodemográfica atual, principalmente nos países ricos e do Norte, de elevação muito forte da idade em que as mulheres passaram a procriar. Assim, a idade conta como o fator de maior peso na queda do potencial reprodutivo da mulher e nas dificuldades de sucesso com TRA sem ovodoação. Como o ciclo FIV produz 
um excesso de ovócitos, muitas vezes as equipes médicas sugerem a doação quando se trata de mulheres de idade mais baixa. Há também o caso de mulheres que se submeteram às TRA por problemas do chamado fator masculino; ou seja, são mulheres que produzem óvulos - e, devido à hiperstimulação hormonal -em grande quantidade. Estas se tornam também doadoras potenciais, se estimuladas a doar parte de seus óvulos excedentes que não seriam fertilizados ou congelados para uso próprio. São vários circuitos de ovodoação no que se configurou como uma "caça aos ovócitos", para que haja aumento da eficiência das técnicas e viabilização da RA num quadro sociodemográfico de escassez do material reprodutivo feminino como o descrito - de mulheres começando a procriação entre 35 e 40 anos de idade -, que não pode, contudo, ser naturalizado.

O debate bioético atual (ABADIE, 2010; COSTA, 2009; HENG, 2005; KAHAN 2009; PARANAMES; FRANCISCO; ALMADA-COLUCCI, 2014; SOUZA 2014), comparando arranjos de ovodoação, considera o compartilhamento de óvulos (doação versus pagamento do tratamento pela receptora) mais ético do que a doação simples, pois, no primeiro caso, a doadora desejaria também se reproduzir, e os riscos e problemas a atravessar seriam justificados pela possibilidade de acesso garantido pelo pagamento efetuado pela outra mulher. Já na doação simples remunerada, trata-se da venda pura e simples de óvulos, por interesse econômico, e a mulher se expõe a riscos de medicamentos e procedimentos fora de qualquer interesse por reprodução ou tratamento.

Essa problemática conduz à formulação de questões éticas na área. Poderia a ovodoação ser modelada como um ato altruísta - por exemplo, manter doadores de óvulos, útero, dentro da própria família (como indica a resolução do CFM)? Deveria ser livre o compartilhamento em qualquer contexto? Poderia ser abordada como exclusivamente comercial - ou seja, venda, por parte de uma mulher, em um mercado reprodutivo?

O modelo altruista, no contexto brasileiro, pode ser exemplificado, por meio de analogia, à doação de sangue: não existe benefício ou compensação e a venda de sangue é um crime - como o é, repetimos, a comercialização de tecidos, células, órgãos humanos. Independentemente de o sangue e o sêmen serem tecidos renováveis, toda a comercialização é vedada pela Constituição em vigor (art. 199, $\$ 4^{\circ}$.). Assim, o Brasil adota um modelo altruísta generalizado 
no que diz respeito a trocas de partes do corpo humano. Dificilmente se pode

deixar de aceitar como centrais os princípios do voluntariado do doador e da não comercialização das práticas envolvendo a doação.

Nos contextos em que a doação compartilhada de óvulos é admitida, forjouse a noção de um modelo de reciprocidade baseado no ajustamento de necessidades, visto como eticamente mais desejável que a mera compra e venda de óvulos. Já a circulação, oferta e demanda por óvulos, útero, num mercado livre, podem ser observadas na internet, em incontáveis websites. ${ }^{11}$ Aparentemente, a aplicação de técnicas se daria em outros países, com destaque para os EUA. Ela pode ter lugar em qualquer país, como o próprio Brasil, já que não há controle dessa prática ilegal. Se visitamos aqueles ou muitos outros sites relacionados, veremos que eles têm em seu menu mulheres brasileiras com ofertas específicas relativas a suas características fenotípicas, e que afirmam a ausência de doenças em sua autopropaganda (figura 1).

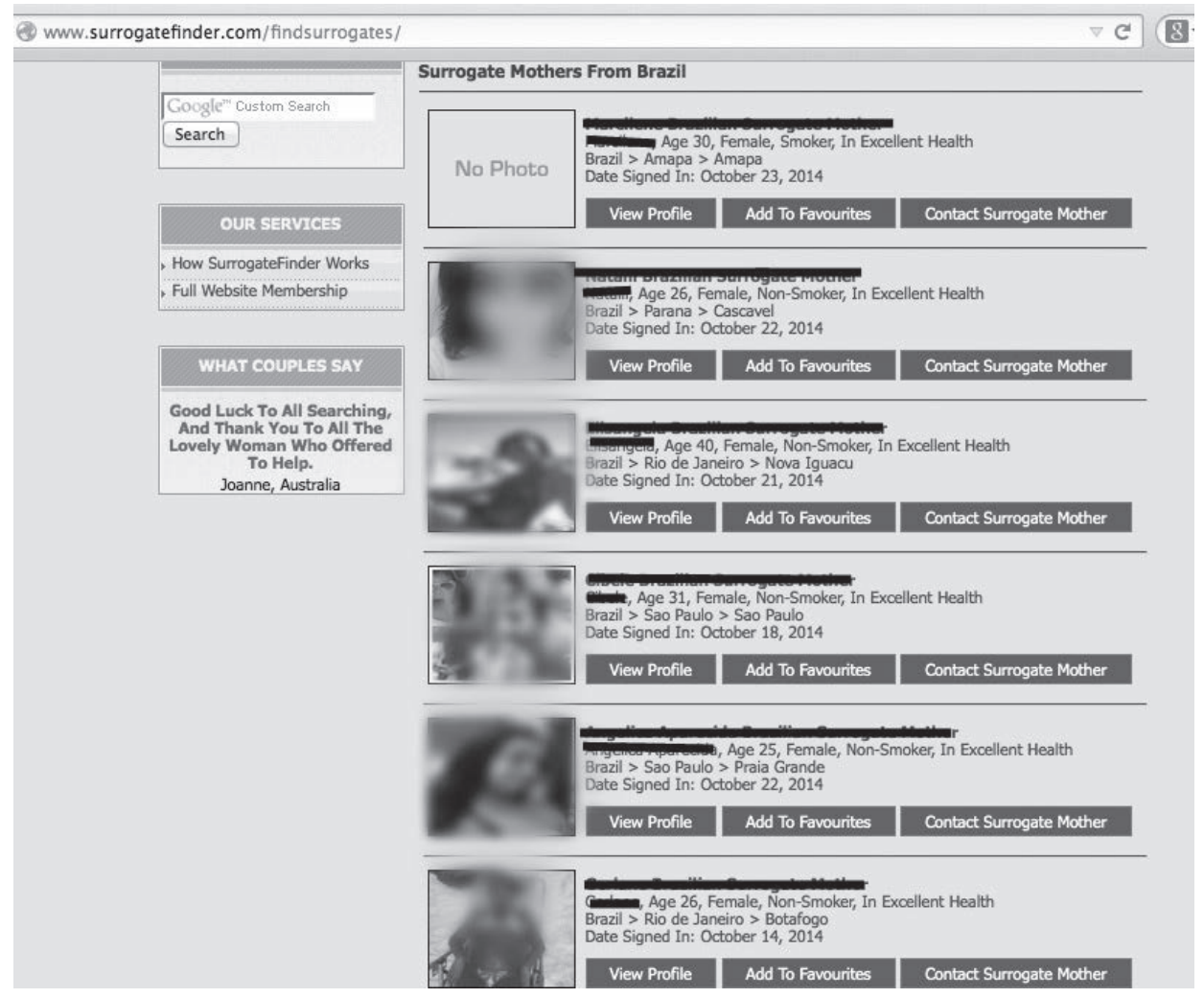


Finalmente, a venda tout court de óvulos e útero (surrogacy), além de sair da esfera dos dois modelos de doação - altruísta e ajustado a necessidades -, em muitos casos envolve mulheres oriundas de países diferentes, com diferentes níveis de riqueza (HENG, 2005). E aqui se configura uma forma de turismo reprodutivo determinado por razões financeiras e de mercado, no sentido de os demandantes buscarem mercados onde suas moedas valem mais, onde o custo de vida é muito menor e onde existem muito mais pessoas necessitadas e, em tese, mais dispostas a vender órgãos, células, alugar seu útero etc. ${ }^{12}$

\section{Considerações finais}

Passados 31 anos do primeiro êxito com a fertilização in vitro no país - o nascimento do primeiro bebê de proveta brasileiro em 1984 -, a aplicação de tecnologias de reprodução assistida continua disponível quase que exclusivamente no setor privado da medicina. Do ponto de vista da regulação, existe em vigor apenas uma norma do Conselho Federal de Medicina, de 2013, que assegura igualdade ao admitir ser ético que pessoas casadas (ou em união), solteiras, homo ou heterossexuais sejam admitidas como usuários das tecnologias de reprodução assistida. Contudo, atrás de uma aparente universalidade na elegibilidade acesso, a não priorização das TRA no âmbito do SUS cria e mantém uma barreira ao acesso de ordem econômica: estão excluídos aqueles que não podem pagar por medicamentos, procedimentos e serviços de reprodução assistida. Tendo em vista o valor social da reprodução humana, esta concentração da medicina reprodutiva no setor privado aprofunda desigualdades e agudiza vulnerabilidades de pessoas excluídas do acesso a essas tecnologias.

Tal situação acaba por estimular a criação de soluções que contrariam o espírito do sistema público de saúde brasileiro, baseado na atenção integral e universal, inclusive expondo as pessoas mais vulneráveis a práticas como a "doação" compartilhada, o que não constitui exatamente uma doação em termos de um ato de liberalidade, muito menos feita de modo altruístico, como orienta o modelo brasileiro para disposição de partes do corpo humano.

Ainda que amplo debate envolva a ausência de filhos e o fato de nem sempre ser possível encaixar a ausência involuntária de filhos (childlessness) em uma categoria de doença - a infertilidade - o Estado não está liberado de sua responsabilidade de buscar soluções para questôes suscitadas pela utilização 
e acesso a essas tecnologias. De fato, é o que indica a previsão constitucional

e legal, com a lei de planejamento familiar de 1996, que abarca não apenas a contracepção, mas também a concepção.

A alocação de recursos orçamentários na área da saúde poderia criar, obviamente, obstáculos quanto à elegibilidade (quem tem direito ou "mais direito" a ter acesso), mas isso não justifica, tendo em vista o entendimento da saúde em sua concepção ampliada e ainda como um direito individual fundamental no Brasil, que o Estado deixe prover soluções nessa área. ${ }^{13}$

\section{Referências}

ABADIE, R. The professional guinea pig: big pharma and the risky world of human subjects. Durham and London: Duke University Press, 2010. 184p.

ALFANO, B. Reprodução assistida: a organização da atenção às infertilidades e o acesso às técnicas reprodutivas em dois serviços público-universitários no Estado do Rio de Janeiro. Tese (Doutorado em Saúde Coletiva) - Universidade do Estado do Rio de Janeiro, Rio de Janeiro, 2014.

ANGEL, J. et al. Aggressive perinatal care for high order multiple gestations. Does good perinatal outcome justify aggressive assisted reproductive techniques? American Journal of Obstetrics and Gynecology, n. 81, p. 253-259, 1999.

ANNAS, G. The shadowlands - secrets, lies and assisted reproduction. New England Journal of Medicine n. 339, p. 935-939, 1998.

BAIRD, D.; WICOX, A. J.; KRAMER, M. S.; Why might infertile couples have problem pregnancies? The Lancet. London, n. 353, p. 1724-1725, 1999.

BECKER G.; NACHTIGALL R. D. Eager for medicalization: the social production of infertility as a disease. Sociology of Health and Illness, v. 14, n. 4, 1992.

BECKER, G. Metaphors in disrupted lives: infertility and cultural constructions of continuity Medical Anthropology Quarterly, v. 8, n. 4, p. 383-410, 1994.

BRASIL. Ministério da Saúde. Portaria GM no 426, de 22 de março de 2005. Política Nacional de Atenção Integral à Reprodução Humana Assistida. Brasília-DF, 2005a.

. Ministério da Saúde. Portaria no 38.806, de julho de 2005. Regulamentação da Política Nacional de Atenção Integral à Reprodução Humana Assistida. Brasília-DF, 2005 b.

. Presidência da República. Casa Civil. Código Civil Brasileiro. Subtítulo II - Das Relaçōes de Parentesco (art 1.591 a 1597). Brasília-DF, 2003.

. Presidência da República. Casa Civil. Subchefia para Assuntos Jurídicos. Lei do Planejamento Familiar $n^{\circ} 9.263$, de 12 de janeiro de 1996. Regula o $\$ 7^{\circ}$ do art. 226 da Constituição Federal, que trata do Planejamento Familiar, estabelece penalidades e dá 
outras providências. Disponível em: <http://legislacao.planalto.gov.br/legisla/legislacao. nsf/Viw_Identificacao/lei\%209.263-1996? OpenDocument>. Acesso em: jan. 2015.

BUTLER, J. Défaire le genre. Paris: Éditions Amsterdam, 2006.

CALLAHAN, J. Critical Notice to John A. Robertson. Children of Choice: freedom and the new reproductive technologies. Stanford Law and Policy Review. Stanford, v. 6, n. 2, p. 121-125, 1995.

CAVALCANTE E. J. Y.; PEREIRA, D. et al. Resultados das técnicas de reprodução assistida em mulheres doadoras de oócitos no ciclo de tratamento Rev Bras. Ginecol. Obstet, v. 27, n. 11, p. 661-4, 2005.

CIOCCI, D.; VIANA. R. G. C.; BORGES JR, E. Aspectos legais na utilização de gametas e embriōes nas técnicas de reprodução humana assistida JBRA Assist Reprod. Rio de Janeiro, v. 13, n. 3, p. 35-36, 2009.

CONSELHO FEDERAL DE MEDICINA. Resolução CFM no 1.358. Normas éticas para a utilização das técnicas de reprodução assistida. 1992.

Resolução CFM no 1.957. Normas éticas para a utilização das técnicas de reprodução assistida. 2010.

Resolução CFM no 2.013. Normas éticas para a utilização das técnicas de reprodução assistida. 2013.

CONSELHO NACIONAL DE SAÚDE. Resolução CNS no 466, de 12 de dezembro de 2012. Ética na pesquisa científica envolvendo seres humanos. Brasília-DF, 2012.

COREA, G. The mother machine: reproductive technologies from artificial insemination to artificial wombs. New York: Harper and Row, 1985.

CORRÊA, M. C. D. V. A tecnologia a serviço de um sonho. Um estudo da reprodução assistida no Brasil. Tese (Doutorado em Saúde Coletiva) - Instituto de Medicina Social, Universidade do Estado do Rio de Janeiro. Rio de Janeiro, 1997.

. Bioética e reprodução assistida. Infertilidade, produção e uso de embriōes humanos.

In: LOYOLA, M. A. (Org). Bioética, reprodução e gênero nas sociedades contemporâneas Campinas e Brasília: Abep e Letras-Livres, 2005a.

Medicina reprodutiva e desejo de filhos. In: GROSSI, M. et al (Org.). Novas tecnologias reprodutivas. Questōes e desafios. Brasília: Letras-Livres, 2003.

CORREAA, M. C. D. V.; LOYOLA, M. A. Novas tecnologias reprodutivas: novas estratégias de reprodução? Physis: Revista de Saúde Coletiva. Rio de Janeiro, v. 9, n. 2, p. 209-234. 1999.

Reprodução e Bioética. A regulação da reprodução assistida no Brasil Cadernos CRH Salvador, v. 18, n. 33, p. 103-112, 2005.

COSTA, A. L. E. Recepção de óvulos doados: a alternativa para a maternidade tardia. JBRA Assit. Reprod., v. 13, n. 3, p. 31-34, 2009. 
COSTA, T. Avaliação do impacto da oferta de tecnologia de alta complexidade em serviço público de referência, na visão dos usuários e dos profissionais. Relatório (Pós-Doutorado em Saúde Coletiva) - Instituto de Medicina Social, Universidade do Estado do Rio de Janeiro, Rio de Janeiro, 2014.

COSTA, T. et al. América Latina e busca por reprodução assistida: perfil da paciente em um serviço público de referência no Rio de Janeiro Brasil JBRA Assist. Reprod. Rio de Janeiro, v. 13, n. 4, p. 21-35, 2009.

CRAFT, I. et al. Limiting multiple births. The Lancet. London, n. 355, p. 1103-1104, 2000.

DAVIS-FLOYD D.; DUMMIT J. (Ed.) Cyborg babies: from techno-sex to techno tots. New York: Routledge, 1998.

DENNY, E. Liberation or oppression? Radical feminism and in-vitro fertilization. Sociology of Health and Illness. London, v. 16, n. 1, p. 63-80, 1994.

DONADIO, N. Óvulo doações por mulheres de 36 anos e férteis com proles definidas durante pequenas cirurgias laparoscópicas. Jornal Brasileiro de Reprodução Assistida. Rio de Janeiro, n. 3, 1999a. Disponível em: <http://www.sbra.com.br>.

. Recrutamento de óvulos doadora entre mulheres férteis que necessitam cirurgias abdominais de pequeno porte. Doações compartilhadas anônimas consentidas. Jornal Brasileiro de Reprodução Assistida. Rio de Janeiro, n. 3, 1999b. Disponível em:<http://www. sbra.com.br>

FACHIN, L. E. A nova filiação: o biodireito e as relações parentais: o estabelecimento da paternidade-filiação e os efeitos jurídicos da reprodução assistida heteróloga. Rio de Janeiro: Renovar, 2003.

FITZSIMMONS, B.; BEBBINGTON, M.; FLUKER, M. Perinatal and neonatal outcomes in multiple gestations: assisted reproduction versus spontaneous conception. American Journal of Obstetrics and Gynecology, n. 179, p. 1162-1167, 1998.

FRANKLIN, S.; RAGONE, H. (Ed.). Reproducing reproduction: kinship, power and technological innovation. Philadelphia: University of Pennsylvania Press, 1998.

GINSBURG, F.; RAPP, R. (Ed.). Conceiving the new world order. The global politics of reproduction. Berkley: University of California Press, 1995.

HARAWAY, D. Simians, cyborgs, and women. The reinvention of nature. London: Free Association Books, 1991.

HARDING, S. The science question of feminism. Ithaca: Cornell Univesity Press, 1986.

HENG, B. H. Ethics, social legal, counseling International egg-sharing to provide donor oocytes for clinical assisted reproduction and derivation of nuclear transfer stem cells. RBM on line, v. II, n. 6, p. 676-678, Oct. 2005.

IACUB, M. Homoparentalité et ordre procreative. In: BORRILLO, ; FASSIN, (Org.). Aù dela du PaCS: L'éxpertise familiale à l'epreuve de l'homossexualité. Paris: PUF, 1999. 
INHORN, M. Infertility around the globe. New thinking on childlessness, gender \& reproductive technologies. Los Angeles: University of California Press, 2002.

KAHAN, S. K. Incentivizing organ donation: a proposal to end the organ shortage. Hofstra Law Review. N. York, v. 38, n. 2, p. 757-791, 2009.

LABORIE, F.; MARCUS-STEIFF, J.; MOUTET, J. Procréations e filiations. Logigues de conceptions et des nominations. L'Homme Paris, v. XXV, n. 3, p. 5-39, 1985.

LOPES, J. R. C.; BRANDI, M. C. C.; COSTA, R. R. et al. Doação compartilhada de óvulos (DOC). Reprodução e Climatério, v. 10, p. 148-150, 1995.

LOWY, I. Prenatal dignosis and the transformation of the epistemic space of human heredity. Hist. Phil. Life Sci, v. 35, p. 99-104, 2013.

LOYOLA, M. A. Bioética, reprodução e gênero nas sociedades contemporâneas: uma introdução. Bioética, reprodução e gênero nas sociedades contemporâneas. Campinas e Brasília: Abep e Letras Livres, 2005.

. Sexualidade e reprodução. Physis: Revista de Saúde Coletiva. Rio de Janeiro, v. 2, n. 1, p. 93-105, 1992.

PARANAMES, S. F.; FRANCISCO, L. S.; ALMADA-COLUCCI, J. What influences oocyte donation when there is no financial compensation? Reprodução e Climatério, v. 29, n. 1, p. 8-12, 2014.

REIS, A. R. G. A fertilização in-vitro no Brasil: a história contada, as estórias. Brasília: Biblioteca do Senado Federal, 1985 (mimeo).

RIBEIRO W. V. et al. Ovorrecepção: perfil das pacientes em lista de espera no programa do Hospital Regional da Asa Sul, Brasília, Distrito Federal. Rev Bras Ginecol Obstet., v. 29, n. 9, p. 459-64, 2007.

ROWLAND, R. Technology and motherhood: reproductive choice reconsidered. Signs, v. 12, n. 3, Spring 1987.

SAMA. The Resource Group for Women and Health. ARTs and women assistance in reproduction or subjugation. Delhi: Sama, 2006.

. The Resource Group for Women and Health. Unravelling the fertility Industry:

challenges and strategies for movement building report. Publication of the International Consultation on Commercial, Economic and Ethical and Aspects of Assisted Reproductive Technologies. Delhi: Sama, 2010.

SCUTT, J. A. (Ed.). Baby machine. Reproductive technology and the comercialisation of motherhood. London: Green Print, 1990.

SOUZA, M. C. B. Current practice of management of infertility in low-resource settings: a Brazilian perspective. Presented to the Seminar "Assisted Reproductive Technologies (ART): Common Terminology and Management in Low-Resource Settings". World Health Organization. WHO/ ICMART/ LIVFF. Geneve, 2008. 
perspective JBRA Assisted Reproduction. Rio de Janeiro, v. 18, n. 2, p. 47-51, 2014.

STEPTOE, P. C.; EDWARDS, R. G. Birth after reimplantation of a human embryo. The Lancet. London, v. ii, n. 366, 1978.

STRATHERN, M. Reproducing the future: anthropology, kinship and reproductive technologies Manchester: Manchester Univresity Press, 1993.

TE VELDE, E.; VAN BAAR, A. L.; VAN KOOIJ, R. J. Concerns about assisted reproduction. The Lancet. London, v. 351, n. 1, p. 524-1.525, 1998.

UNITED KINGDOM. Department of Health \& Social Security. Report of the Committee of Inquiry into Human Fertilisation and Embryology. Chairman: Dame Mary Warnock, DBE. Command of Her Majesty. Her majesty's stationery office: London, July 1984 (Reprinted 1988). 103p.

VAN STEIRTEGHEN, A. Outcome of assisted reproductive technology. The New England Journal of Medicine, n. 338, p. 194-195, 1998.

WORLD HEALTH ORGANIZATION. Current practices and controversies in assisted reproduction report of a meeting on. Medical, Ethical and Social Aspects of Assisted Reproduction. Geneva, WHO, 2002.

ZEGERS-HOCHSCHILD, F. et al. Assisted reproductive technologies (ART) in Latin America: the Latin American Registry, 2012. JBRA Assised Reproduction. Rio de Janeiro, v. 18, n. 4, p. 127-135, 2014.

- International Comittee for Monitoring Assisted Reproductive Technology (ICMART) and the World Health Organization (WHO) revised glossary of ART technology. Fertility and Sterility vol 92. N. 5 november, 2009.

\section{Notas}

${ }^{1}$ As definições e nomenclatura dos aspectos incluídos sob o conjunto heterogêneo de TRA são um problema que se tornou agudo. A homogeneização de definições é o que viabiliza a possibilidade de monitoramento de resultados, efeitos adversos e colaterais da RA. Assim, o esforço internacional da OMS para estabelecer um glossário com definições fundamentais sobre, por exemplo, o que é uma gravidez bioquímica, a taxa de gravidez clínica, estimulação ovariana controlada, peso baixo, peso extremamente baixo do recém-nascido, entre muitos outros, foi levado a cabo, sem o que não seria possível um follow-up dos resultados das TRA (ZEGERS-HOSCHILD et al., 2009).

${ }^{2}$ Neste artigo abordamos técnicas que implicam a fertilização in-vitro (FIV, Icsi, Gift, etc.), por promoverem o fato sociotécnico do embrião humano manipulável fora do corpo da mulher. Como sabido, do conjunto da reprodução assistida fazem parte também técnicas menos complexas e mais antigas, como as inseminações artificiais, o coito programado etc.

${ }^{3}$ Estas células e embriōes excedentes, inicialmente um problema da RA, passaram a ser recuperados em novas propostas biotecnológicas, principalmente na pesquisa e também na doação. 
${ }^{4}$ A ICSI (injeção intracitoplasmática de espermatozoide nos ovócitos) é uma variante da fertilização in vitro surgida em meados dos anos 1990, que representou um marco por ter sido desenvolvida para tratar infertilidades masculinas (homens cujo sêmen tem baixa contagem de espermatozoides ou outras alterações que impedem a fecundação natural). A invasividade da ICIS é ainda maior. A individualização laboratorial de cada espermatozoide a ser injetado no óvulo, escolha feita pelo biólogo ou biomédico com base em critérios científicos, leva a que, à guisa de precaução, se acrescente mais uma biotecnologia ao processo: o diagnóstico preimplantatório (DPI) para seleção de embriôes saudáveis (técnica que também possibilita seleção com base em outras características, onde eticamente admitido).

${ }^{5}$ Para séries históricas de gestações multigemelares, e muitos outros dados, conferir os Relatórios Anuais Rede LARA disponíveis em: < http://www.redlara.com/>

${ }^{6}$ Neste ponto, as autoras agradecem ao doutorando do IMS-UERJ, Koichi Kameda, jurista que colaborou neste artigo com um levantamento sobre o estado da arte da concessão ou não de liminares a processos de demanda de acesso à FIV. Cf: Poder Judiciário do Rio de Janeiro. Diretoria Geral de Gestão do Conhecimento. Departamento de Gestão e Disseminação do Conhecimento Banco do conhecimento - fertilização in vitro (atualizado em 21 nov. 2011).

${ }^{7}$ Caberia aqui discutir a priorização na alocação de recursos em saúde, questão que tem sido considerada no âmbito judicial, nas decisões para negar acesso a TRA, a partir a aplicação de princípios como a reserva do possivel. Esse vasto e importantíssimo debate ultrapasse os limites do presente trabalho.

${ }^{8}$ Consultar: <http://www.queroterumfilho.com.br>

${ }^{9}$ Disponível em: http://www.vidalink.com.br/institucional_trajetoria_english.htm

${ }^{10}$ Abadie (2010) discute o pagamento de voluntários de pesquisas, colocando em perspectiva o fato de, no plano da ética em pesquisa, a preocupação isolada com a proibição de remuneração pode, muitas vezes, impedir que se desvelem outros aspectos subjacentes às realidades dos contextos de realização de testes e das pesquisas com seres humanos. A remuneração de participantes de pesquisa médica é uma possibilidade em outros países, não sendo sinônimo de exploração, como mostra em seu trabalho citado; já a transparência nas negociaçôes com partes do corpo e uma regulação bastante clara e estrita (seja para admitir ou não) pode garantir mais igualdade e, portanto, autonomia nas decisóes.

${ }^{11}$ Por exemplo: <http://www.premiereggdonors.com>; <http://www.eggdonor4u.com/>; <http:// www.surrogatefinder.com $>$.

${ }^{12}$ Este tipo de turismo médico se diferencia de outro parecido onde mulheres, homens, casais hetero ou homossexuais viajam porque desejam uma gestação à qual não poderiam ter acesso em seu país de origem em função da regulação na aplicação das técnicas (em função da configuração do casal, idade das pessoas, estado civil), mas que por meio do pagamento aos profissionais e clínicas no setor privado garantiriam seu acesso; contextos onde a (des)regulação possibilita qualquer prática reprodutiva envolvendo surrogacy, comercialização de células e tecidos humanos desde que ocorram no setor privado lucrativo.

${ }^{13}$ M. Corrêa participou de todas as etapas da pesquisa e redação e revisão final. M. A. Loyola contribuiu igualmente nas mesmas etapas. 


\section{Assisted reproductive technologies in Brazil:} options to improve access

This article revisits the pattern of assimilation and dissemination of assisted reproductive technologies (ART) in Brazil, characterized by extreme concentration of this technology in the private medical sector and very low setting in the application of these techniques. This pattern has generated enormous difficulties and barriers to access to these techniques, basically for economic reasons. From the presentation of the overview of the history of ART, the article focuses on two cases that may propose solutions for excessive exclusion access, although it does not modify the same privatization logic that marks RT in the country, since the problem of infertility was not prioritized, so far, by the Unified Health System. The first, brought by the pharmaceutical industry, consists of a subsidized purchasing program of drug users by the so-called Programa Acesso. The second proposal, known as shared ovules donation, implies the exchange between two women, of biologically scarce reproductive materials (oocytes). This exchange occurs, in general, from a woman who has ovules and cannot afford treatment and another who has no ovules to reproduce, and pays for the treatment of the donor. Both proposals diffuse a legal framework rather poorly regulated in terms of the application of ART, but prohibit practices not authorized in the Constitution and criminalized in penal law such as the sale of human organs and tissues in general, as well as volunteers to payment tests for research. In terms of methodology, the article assumes monographic character and literary debate, but is also based on the collection of recent secondary data, as well as numerous empirical studies conducted over the last 25 years by the authors.

> Key words: assisted reproduction; biomedical technology; access; reproductive rights. 